\title{
Preliminary feasibility study for the use of an adsorption/bio- regeneration system for molinate removal from effluents
}

\author{
Mónica Silva $^{\mathrm{a}}$, Ana Fernandes ${ }^{\mathrm{a}}$, Adélio Mendes ${ }^{\mathrm{a}}$, Célia M. Manaia ${ }^{\mathrm{b}}$, \\ Olga C. Nunes ${ }^{\mathrm{a}, *}$ \\ ${ }^{\text {a } L E P A E-D e p a r t a m e n t o ~ d e ~ E n g e n h a r i a ~ Q u i ́ m i c a, ~ F a c u l d a d e ~ d e ~ E n g e n h a r i a, ~ U n i v e r s i d a d e ~ d o ~ P o r t o, ~ P o r t o, ~ R . ~ D r . ~ R o b e r t o ~ F r i a s, ~}$ \\ 4200-465 Porto, Portugal \\ ${ }^{\mathrm{b}}$ Escola Superior de Biotecnologia, Universidade Católica Portuguesa, R. Dr. António Bernardino de Almeida, 4200-072 Porto, Portugal
}

Keywords: Molinate; Adsorption; Amberlite XAD-4; Bio-regeneration

\begin{abstract}
This work studies the feasibility of the use of a combined physical-biological remediation procedure for treatment of effluents contaminated with molinate, where the herbicide is removed through adsorption and biodegraded in a subsequent stage, with the regeneration of the adsorbent.

In order to select the most adequate absorbent for molinate, different materials were tested, namely pine bark, activated carbon and resin Amberlite XAD-4. Activated carbon and resin Amberlite XAD-4 were the most efficient on the removal of molinate from solutions, although the activated carbon used proved not to be bio-regenerable. It was also observed that factors such as temperature, $\mathrm{pH}$, and conductivity did not affect significantly molinate adsorption onto resin Amberlite XAD-4.

Resin Amberlite XAD-4 was successfully bio-regenerated, being observed that biodegradation was mainly dependent on spontaneous desorption of the molinate. After bio-regeneration, the resin could be re-utilised as adsorbent.
\end{abstract}

\section{Introduction}

Pesticides are found in water, food, air and soil due to their widespread use and to the way they are applied. More than $60 \%$ of the pesticides used in agriculture are herbicides [1]. Molinate ( $S$-ethyl $N, N$-hexamethylene-1carbamate) is a systemic thiocarbamate herbicide used worldwide to control weeds in rice paddies. Contamination with molinate, as a result of it's application, may occur on surface and ground waters and soils. In several countries, molinate residues have been detected in receiving natural waters at levels up to $100 \mathrm{mgl}^{-1}[2-$

*Corresponding author. Tel.: + 351-22-5081917; fax: + 35122-5081449.

E-mail address: opnunes@fe.up.pt (O.C. Nunes).
4]. Despite of being considered a moderately toxic compound, molinate, and specially its metabolites, are toxic to warm blooded animals and have been implicated to have adverse reproductive and neurotoxic effects [5]. Consequently, it is important to develop strategies for treatment of molinate polluted sites and avoidance of future contaminations.

The decontamination of surface waters containing low concentrations of pollutants is usually difficult and expensive. Under these conditions, the use of physical methods, such as adsorption, is normally preferred to biological treatment, which has a reduced efficacy when bioavailability of the xenobiotic is low. Treatment of gas or liquid effluents through the adsorption of xenobiotics has been widely studied and applied [6-14]. The major disadvantage of such processes is that at the end of the 
treatment, the adsorbent is contaminated with the pollutant. In this context, the use of biological treatment, a clean methodology, can be efficiently used for adsorbent regeneration. The use of biological systems for biodegradation of adsorbed pollutants falls into two main categories. In one of these categories, biological growth on the adsorbent is simultaneous with the adsorption of the pollutant. This approach has been used with different pollutants and the adsorbent more commonly used is activated carbon, receiving the name biological-activated-carbon (BAC) $[11,12,15]$. The other category uses a two-step approach, in which the pollutant is first both concentrated and removed from the environment through adsorption, being the adsorbent bio-regenerated, subsequently $[9,16]$. The use of this methodology is not so widespread as the previous one, but it has the advantage of avoiding the risk of biological contamination of the effluent. Additionally, off-line bio-regeneration is considered a suitable choice, under certain circumstances, such as limited availability of nutrients or high loading of organic compounds [16].

The main long-term objective of this study is to evaluate the feasibility of a two-step molinate decontamination process. The first stage, to take place in the field, consists on the herbicide removal from the effluent through adsorption. The second stage consists in the bio-regeneration of the adsorbent, in a treatment plant. The implementation of a two-step process relies on two facts: (1) the necessity to remove the herbicide from liquid effluents, with its simultaneous concentration making the bio-treatment process feasible; and (2) the need to avoid environmental contamination with the bacterial culture which promotes the biodegradation of the herbicide. This paper reports the preliminary studies on the selection of the adsorbent, and on its bioregeneration capabilities, using a bacterial mixed culture (mixed culture DC), able to mineralize molinate [17].

\section{Materials and methods}

\section{Chemicals}

Molinate ( $S$-ethyl $N, N$-hexamethylene-1-carbamate) of $97 \%$ purity was purchased from Herbex, Produtos Químicos (Estoril, Portugal) and cycloate ( $S$-ethyl $N$ cyclohexyl- $N$-ethyl) from Riedel-de Häen (Germany). Some properties of molinate are given in Table 1.

\section{Adsorbents}

Several materials, previously reported as good adsorbents, were tested: pine bark, from Pinus pinaster, an excedentary product from wood processing industry in Portugal [18]; activated carbon, a widespread used adsorbent due to its very high surface area and microporous volume; and resin Amberlite XAD-4 [8], a synthetic resin constituted by a non-ionic crosslinked polymer (polystyrene reticulated with vinylbenzene) which derives its adsorptive properties from its patented macroreticular structure (large internal surface), and the aromatic nature of its surface. Table 2 summarises some of characteristics of these adsorbents.

Pine bark was obtained from a wood processing industry from North of Portugal; activated carbon (granular) was obtained from Chemviron (France); and resin Amberlite XAD-4 was obtained from Rohm \& Haas (France).

\section{Adsorbent preparation}

Pine bark was initially heated overnight at $150^{\circ} \mathrm{C}$. Air was removed by vacuum. Pine bark was then sieved $(0.250 \mathrm{~mm})$, washed with distilled water, and filtrated through a paper filter Whatman 42. Activated carbon was treated similarly, except that was heated overnight at $200^{\circ} \mathrm{C}$. Resin Amberlite XAD-4 was washed with distilled water, then with methanol p.a., and again with distilled water. It was then sieved $(0.250 \mathrm{~mm})$ and washed five to seven times with $50 \mathrm{ml}$ of distilled water through a paper filter, until a value of $4 \mu \mathrm{Scm}^{-1}$ was recorded for the washing solution.

Table 1

Physical properties of molinate

\begin{tabular}{ll}
\hline Formula & $\mathrm{C}_{9} \mathrm{H}_{17} \mathrm{NOS}$ \\
\hline Molecular weight & $187.3 \mathrm{~g} \mathrm{~mol}^{-1}$ \\
Water solubility & $800-912 \mathrm{mg} \mathrm{l}^{-1}$ \\
Organic coefficient & 186 \\
\hline
\end{tabular}

Data from Mabury et al. [2].

Table 2

Main characteristics of the selected adsorbents

\begin{tabular}{|c|c|c|c|}
\hline Adsorbent & $\begin{array}{l}\text { Surface } \\
\text { area }\left(\mathrm{m}^{2} / \mathrm{g}\right)\end{array}$ & $\begin{array}{l}\text { Average } \\
\text { pore } \\
\text { diameter } \\
(\mathrm{nm})\end{array}$ & $\begin{array}{l}\text { Pore } \\
\text { volume } \\
\left(\mathrm{cm}^{3} \mathrm{~g}^{-1}\right)\end{array}$ \\
\hline Pine bark & $0.3-0.5$ & 70 & 0.4 \\
\hline $\begin{array}{l}\text { Activated carbon- } \\
\text { Chemviron }^{\mathrm{a}}\end{array}$ & 1490 & 17 & 0.9 \\
\hline $\begin{array}{l}\text { Resin Amberlite } \\
\text { XAD- } 4^{\text {b }}\end{array}$ & 750 & 10 & ND \\
\hline
\end{tabular}

${ }^{\text {a }}$ Pinto [25].

${ }^{\mathrm{b}}$ Rhom \& Haas, France. 


\section{Determination of the adsorption isotherm of molinate on resin Amberlite X AD-4}

Seven molinate solutions with different concentrations $\left(190,215,151,350,441,456\right.$ and $\left.526 \mathrm{mgl}^{-1}\right)$ were prepared in mineral medium B [17]. Each experiment was conducted in batch, in duplicate, using Erlenmeyer flasks with cap with teflon liner. Samples of $0.500 \mathrm{~g}$ wet resin Amberlite XAD-4 (corresponding to $0.196 \mathrm{~g}$ dry resin) were mixed with $100 \mathrm{ml}$ of the less concentrated solution of molinate $\left(190 \mathrm{mg}^{-1}\right)$. The suspensions were shaken $(120 \mathrm{rpm})$ at a constant temperature of $30^{\circ} \mathrm{C}$. Preliminary kinetic experiments demonstrated that equilibrium time was reached after $24 \mathrm{~h}$. Samples were collected after the equilibrium being reached and centrifuged at $14000 \mathrm{rpm}$. Supernatants were stored at $-20^{\circ} \mathrm{C}$ until analysis of herbicide content by HPLC as described previously [17]. Resin was filtered through a membrane (porosity: $0.2 \mu \mathrm{m}$, diameter: $47 \mathrm{~mm}$ ) under vacuum, and re-suspended into the second less concentrated molinate solution. The same procedure was followed until the more concentrated molinate solution $\left(526 \mathrm{mg}^{-1}\right)$ was used. The adsorbed amount of molinate was obtained by the difference between the initial and the equilibrium concentration of aqueous phase molinate.

The desorption of adsorbed molinate on resin Amberlite XAD-4 was also monitored. Resin samples with previously adsorbed molinate were filtered as described above, re-suspended in $100 \mathrm{ml}$ of mineral medium B and the suspensions were shaken at $120 \mathrm{rpm}$, $30^{\circ} \mathrm{C}$, for $24 \mathrm{~h}$. Samples were collected and molinate analysed as described above.

An alternative procedure was used to obtain the adsorption equilibrium isotherms of molinate in aqueous solutions at $10^{\circ} \mathrm{C}$ and $30^{\circ} \mathrm{C}$. Samples of resin Amberlite XAD-4 were mixed with different volumes of aqueous molinate solutions at different concentrations, in order to achieve the adsorption equilibrium values needed to describe the isotherms. Namely the following volumes and concentrations were used: $50,100,100,150,300,150$ and $200 \mathrm{ml}$ of about 423, 439, 602, 746, 556, 729 and $783 \mathrm{mgl}^{-1}$ molinate aqueous solutions, respectively. Samples of $0.500 \mathrm{~g}$ (wet weight) of resin were used for the assays with lower initial molinate concentrations (423-589 $\mathrm{mg}^{-1}$ ), while for those assays with 729 and $783 \mathrm{mgl}^{-1}$ molinate aqueous solutions $0.250 \mathrm{~g}$ of wet resin was used. The experimental conditions and sampling were the same as described before.

In order to evaluate the effect of $\mathrm{pH}$, molinate aqueous solutions of approximately $700 \mathrm{mg}^{-1}$ were adjusted to $\mathrm{pH} 5,6,8$ and 9 with $\mathrm{NaOH}$ $2 \mathrm{M}$.

\section{Growth of mixed culture DC with adsorbed molinate}

\section{Adsorption of molinate onto resin Amberlite $X$ AD-4}

Resin was treated as described above and sets of about $0.500 \mathrm{~g}$ of wet resin were suspended with $100 \mathrm{ml}$ of distilled water. After autoclaving ( $30 \mathrm{~min})$, the suspension was filtered aseptically as described above, to eliminate water. Resin samples obtained using this procedure were re-suspended in $50 \mathrm{ml}$ of mineral medium B with different concentrations of molinate $\left(100,260,470\right.$ and $\left.595 \mathrm{mg}^{-1}\right)$. The suspensions were shaken for $24 \mathrm{~h}$ at $30^{\circ} \mathrm{C}$. Sampling and molinate analysis were performed as described before.

\section{Growth of mixed culture DC with adsorbed molinate}

Resin samples with molinate previously adsorbed were inoculated with $10 \%(\mathrm{v} / \mathrm{v})$ of a pre-grown mixed culture DC in exponential phase. Cultures were incubated at $30^{\circ} \mathrm{C}$ and $120 \mathrm{rpm}$. Three sets of controls were incubated simultaneously: (1) non-inoculated (abiotic control), to control sterility, abiotic losses and desorption of molinate; (2) without resin, to confirm the growth at expenses of molinate; (3) without molinate, to confirm that resin components were not supporting growth. Cell growth was monitored spectrophotometrically $\left(\mathrm{OD}_{610 \mathrm{~nm}}\right)$. Cells dry weight was obtained through a calibration curve of optical density versus cells dry weight [17]. Culture samples were collected along regular intervals and free molinate content was determined by HPLC as described previously [17].

\section{Extractions of molinate adsorbed onto resin amberlite X AD-4}

Each sample was extracted five times with $2 \mathrm{ml}$ of methanol and $5 \mathrm{~min}$ of vortexing. Cycloate was used as internal standard, at a concentration of $5.4 \mathrm{gl}^{-1}$. The final extract, consisting on the mixture of the five separate extracts was dried under a nitrogen current, resuspended in $500 \mu \mathrm{L}$ of methanol and dilutions thereof analysed by HPLC.

\section{Assessment of bio-regenerated resin Amberlite X AD-4 adsorption capacity}

Resin was treated, sterilised, and filtrated as described before. Samples of about $0.500 \mathrm{~g}$ of wet resin were resuspended in $100 \mathrm{ml}$ of a sterile aqueous molinate solution $\left(657 \mathrm{mgl}^{-1}\right)$. The suspensions were shaken at $30^{\circ} \mathrm{C}$ and $120 \mathrm{rpm}$, for $24 \mathrm{~h}$. Sampling of liquid phase and molinate analysis were performed as described before. The suspensions were filtered again, and another two adsorption cycles were repeated, using the same molinate aqueous solution. At the end, another cycle 
was repeated using a molinate solution with the equilibrium concentration of the last step $\left(390 \mathrm{mg} \mathrm{l}^{-1}\right)$.

After the last adsorption cycle, filtered resin samples were re-suspended in $50 \mathrm{ml}$ of mineral medium B. Two samples of resin were inoculated with mixed culture DC $(10 \%, v / v)$. Abiotic controls were run in parallel. Cultures and controls were incubated at $30^{\circ} \mathrm{C}$ and $120 \mathrm{rpm}$. After 20 days of incubation, resin samples were filtered using the same procedure described before and sterilised by autoclaving. In order to assess resin reutilisation potentialities, these resin samples were submitted to a new adsorption cycle, using an aqueous molinate solution with a concentration of $593 \mathrm{mgl}^{-1}$.

\section{Results and discussion}

\section{Selection of molinate adsorbents}

Preliminary studies were conducted in order to select the most adequate adsorbent(s) to use in the combined method to decontaminate polluted waters. The selection of molinate adsorbents was made having two main aspects in consideration - the capacity of adsorption, aiming the use of small amounts of adsorbent to be processed, and the possibility of bio-regeneration of the adsorbent. They were also selected according to their availability, price and previous descriptions about adsorption efficiency. Several adsorbents were tested, namely, pine bark, activated carbon and resin Amberlite XAD-4. Adsorption equilibrium values were obtained for each material at the same conditions, adsorbent weight, molinate solution volume and concentration (Table 3). These data provide a qualitative comparison of the adsorbents capacities to retain molinate. Pine bark adsorbed the herbicide almost instantaneously (about $1 \mathrm{~min}$ ), however, presented a very low adsorption capacity and was not further studied. Under the same conditions, activated carbon and resin Amberlite XAD4 showed a very high adsorption capacity when compared to the previous adsorbents, and due to their good adsorbing properties, were selected for bioregeneration tests. Activated carbon and resin Amberlite XAD-4 adsorbed ca. 10 to 100 times more molinate than

Table 3

Molinate adsorbed concentration $(q)$ for samples of $0.500 \mathrm{~g}$ of adsorbent (wet weight) in $50 \mathrm{ml}$ of an approximately $500 \mathrm{mg}^{-1}$ molinate aqueous solution, at $30^{\circ} \mathrm{C}, 120 \mathrm{rpm}$, for $24 \mathrm{~h}$ (qualitative experiment)

\begin{tabular}{ll}
\hline Adsorbents & $\begin{array}{l}q\left(\mathrm{mg}^{\text {adsorbed }}\right. \\
\left.\text { molinate }^{-1} \text { dry adsorbent }\right)\end{array}$ \\
\hline Pine bark & 10 \\
Activated carbon & 113 \\
Resin Amberlite XAD-4 & 144 \\
\hline
\end{tabular}

the other tested materials. When compared with fly ash [19] and iron-aluminium pillared clay [20], molinate adsorption capacity of resin Amberlite XAD-4 is ca. 50100 times higher, respectively.

To promote bio-regeneration it was used a bacterial mixed culture (DC) described as able to mineralize molinate in free solution [17]. Preliminary biodegradation studies showed that molinate adsorbed onto the activated carbon used in this study did not support growth of the bacterial culture. By the opposite, mixed culture DC was able to grow at expenses of molinate adsorbed onto resin Amberlite XAD-4. These results can be explained because under the bacterial growing conditions molinate desorbs from the resin Amberlite XAD-4, but not from activated carbon.

Therefore, among the adsorbents tested resin Amberlite XAD-4 was considered the most suitable for further implementation of a combined system to decontaminate waters containing molinate.

\section{Adsorption isotherms of molinate onto resin Amberlite X AD-4}

Accurate adsorption equilibrium isotherms were determined for modelling and optimisation purposes. Adsorption isotherms obtained at $30^{\circ} \mathrm{C}$ and the respective experimental and fitted data to Freundlich equation are represented graphically in Fig. 1(A and B), for both aqueous and mineral medium solutions. It can be verified that the medium with a conductivity of $489 \mathrm{mS} \mathrm{cm}^{-1}$ had no significant influence on the molinate adsorption (Table 4). The fitting curve obtained of the molinate adsorption equilibrium values in mineral medium was $q=93.64 \times C^{1 / 3.01}$ while in aqueous solution was $q=92.44 \times C^{1 / 2.94}$, where $q$ is the adsorbed concentration in $\mathrm{mg}$ of adsorbed molinate per gram of dry resin and $C$ is the molinate concentration in the liquid phase in $\mathrm{mgl}^{-1}$. The differences between these two curves are within the experimental error calculated for the replicate experimental values, assuming a $t$ student distribution and for $95 \%$ confidence (maximum of $6 \%$ ). Desorption experiments confirmed the reversibility of the adsorption process. Three experimental desorption values are shown Fig. 1B, along with the Freundlich fitting for mineral medium reported previously.

At $10^{\circ} \mathrm{C}$ the isotherm obtained was: $q=100.84 \times$ $C^{1 / 3.15}$, being about $5 \%$ the maximum relative difference between this isotherm and that registered at $30^{\circ} \mathrm{C}$. This difference is within the experimental error $(6 \%)$, indicating that, in the range of $10-30^{\circ} \mathrm{C}$, temperature had a weak effect on molinate adsorption (Table 4). Similar conclusions were obtained by González-Pradas et al. [21] and by Gimeno et al. [14] for the herbicides diquat and MCPA, respectively. 

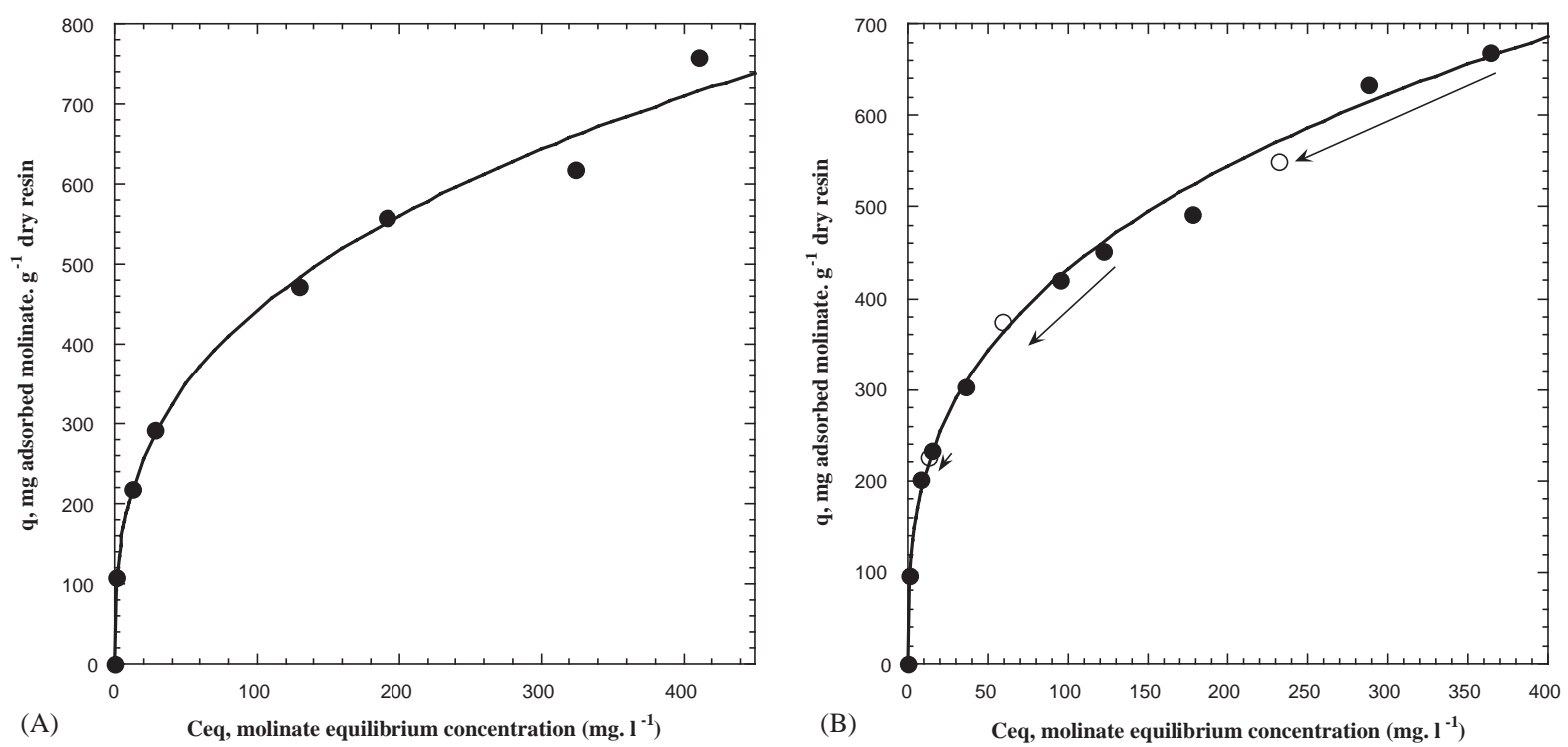

Fig. 1. Adsorption isotherms of molinate onto Amberlite XAD-4 and molinate sorption equilibrium values obtained by adsorption and desorption processes, at $30^{\circ} \mathrm{C}$. (A) Molinate aqueous solutions and (B) molinate solutions in mineral medium B. • - experimental adsorption values; $\bigcirc$ - experimental desorption values; $\rightarrow$ - desorption direction; —— Freundlich equation.

Comparing the values of the adsorbed concentration $(q)$ for molinate solutions at the four $\mathrm{pH}$ values tested (5-9), it was observed that $4 \%$ is the maximum relative difference obtained (Table 4). In this way, it is possible to conclude that molinate adsorption is independent of the solution $\mathrm{pH}$ in the range tested. Indeed, these data match the molinate isotherm obtained for the aqueous solutions (Fig. 1A).

In summary, the variation of the abiotic factors tested did not affect the adsorption process suggesting that resin Amberlite XAD-4 can be successfully used to treat molinate polluted waters, under environmental conditions.

\section{Bio-regeneration of resin Amberlite XAD-4}

Bio-regeneration was performed using mixed culture DC, able to mineralise molinate to values below $0.9 \mathrm{mgl}^{-1}$, without accumulation of degradation products [17]. In an initial step, molinate mineral solutions with concentrations of approximately 100, 260, 470 and $595 \mathrm{mg}^{-1}$ were used to adsorb the herbicide onto resin Amberlite XAD-4. When equilibrium was reached, the amounts of adsorbed molinate $(\mathrm{mg})$ per gram of dry resin were, respectively $25,67,119$ and 150 , while equilibrium concentrations in free solution ranged between values below the detection limit of the HPLC $\left(0.9 \mathrm{mg}^{-1}\right)$ and $5 \mathrm{mg}^{-1}$, as predicted by the adsorption isotherm (Fig. 1B). The capability of mixed culture DC to regenerate resin Amberlite XAD-4 with adsorbed molinate was assessed, using these concentrations of
Table 4

Effect of different abiotic parameters on the adsorption of molinate onto resin Amberlite XAD-4. Molinate adsorbed concentration $(q)$ for samples of $0.500 \mathrm{~g}$ of resin (wet weight) in $100 \mathrm{ml}$ (or $150 \mathrm{ml}$ ) of an approximately $700 \mathrm{mgl}^{-1}$ molinate aqueous solution (qualitative results)

\begin{tabular}{ll}
\hline Parameters & $\begin{array}{l}q\left(\mathrm{mg}^{2} \text { adsorbed }\right. \\
\text { molinate }^{-1} \text { dry resin) }\end{array}$ \\
\hline pH 5 & 323 \\
pH 6 & 311 \\
pH 8 & 310 \\
pH 9 & 324 \\
Conductivity $489 \mathrm{mS} \mathrm{m}^{-1}$ & \\
(mineral medium B) $_{10^{\circ} \mathrm{C}^{\mathrm{a}}}$ & 336 \\
$30^{\circ} \mathrm{C}$ & 430 \\
\hline
\end{tabular}

\footnotetext{
${ }^{\mathrm{a}}$ Or $150 \mathrm{ml}$
}

immobilised herbicide, as the only source of carbon and nitrogen. Mixed culture DC was simultaneously grown with the same initial molinate concentrations (approximately $100,260,470$ and $595 \mathrm{mg}^{-1}$ ) in free solution, in order to compare kinetic parameters, and in mineral medium containing resin without molinate to confirm the incapability of mixed culture DC to use the adsorbent as nutrient. Growth and free solution molinate concentration were monitored along the time (Fig. 2). By the end of the growth, molinate remaining on the resin was extracted and analysed.

At lower concentrations of adsorbed herbicide (about 25 and $67 \mathrm{mg}$ adsorbed molinate per g dry resin), 

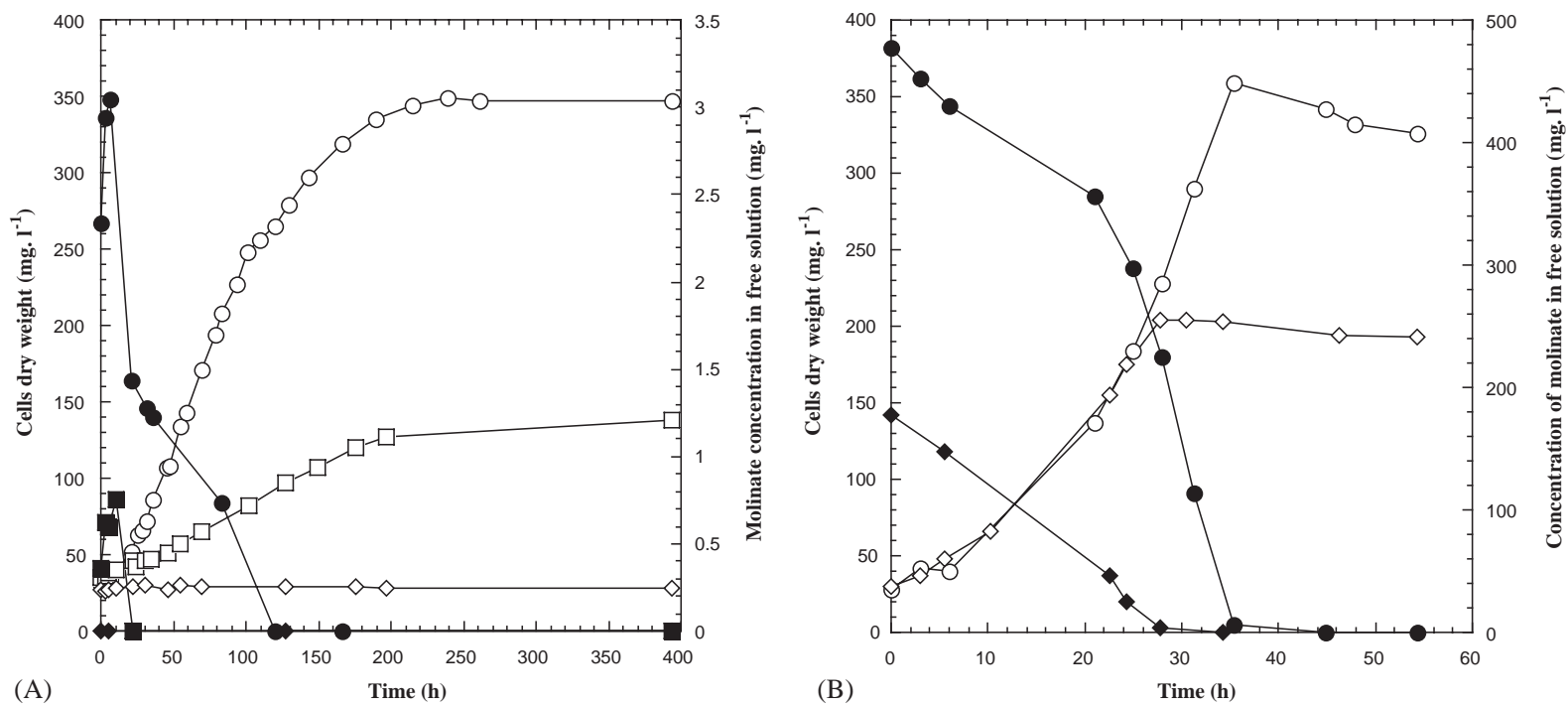

Fig. 2. Growth and free molinate depletion by mixed culture DC. (A) Cultures grown with molinate adsorbed onto resin Amberlite XAD-4. $\bigcirc, \bullet$ - biomass and free molinate, respectively, corresponding to $150 \mathrm{mg}$ molinate per g of dry resin. $\square, \mathbf{\square}-$ biomass and free molinate, respectively, corresponding to $119 \mathrm{mg}$ molinate per $\mathrm{g}$ of dry resin. $\diamond$, $\diamond$ biomass and free molinate, respectively, corresponding to $67 \mathrm{mg}$ molinate per g of dry resin. (B) Cultures grown with molinate in free solution. $\bigcirc$, $\bullet-$ biomass and molinate at a concentration of $595 \mathrm{mgl}^{-1}$, respectively. $\diamond, \diamond$ - biomass and molinate at a concentration of $260 \mathrm{mg} \mathrm{l}^{-1}$, respectively.

corresponding to equilibrium concentrations below the detection limit of the HPLC, bacterial growth did not occur, although equivalent amounts of free molinate were consumed while supporting growth. The analysis of the methanolic extracts of the resin containing the adsorbed herbicide revealed that almost all molinate remained adsorbed to the resin (about 24 and $53 \mathrm{mg}$ adsorbed molinate per g dry resin), confirming that it was not consumed. By the opposite, mixed culture DC was able to grow with higher initial adsorbed molinate concentrations (about 119 and $150 \mathrm{mg}$ adsorbed molinate per g dry resin). However, when compared with cultures on molinate in free solution it was observed that growth rates were clearly decreased when cells were cultured with adsorbed molinate. In fact, growth rates were approximately $0.08 \mathrm{~h}^{-1}$ with free molinate while in the presence of adsorbed herbicide decreased to 0.01 and $0.03 \mathrm{~h}^{-1}$, to 119 and $150 \mathrm{mg}$ adsorbed molinate per g dry resin, respectively. The analysis of methanolic extracts of remaining adsorbed molinate, showed that by the end of the growth the same amount of herbicide was not degraded in both cultures (approximately $60 \mathrm{mg}$ adsorbed molinate per g dry resin). These results lead to the conclusion that, despite of being a slower process, mixed culture DC was able to use the adsorbed molinate as the only source of carbon, nitrogen and energy, promoting simultaneously resin bio-regeneration. However, resin bio-regeneration was not complete, since the extent of molinate degradation was limited by the equilibrium concentrations reached. To equilibrium concentrations below $0.9 \mathrm{mgl}^{-1}$ (detection limit of the HPLC used), observed to correspond to approximately $60 \mathrm{mg}$ adsorbed molinate per g dry resin, bioavailable molinate is too low to support growth, and the remaining adsorbed herbicide is not biodegraded. In order to increase the extent of molinate desorption, the synthetic surfactants sodium dodecyl sulphate (SDS) or Tween 80 were added at a non-inhibitory concentration of $1 \mathrm{gl}^{-1}$. Also the effect of increased ionic strengh of the medium was tested using $10 \mathrm{gl}^{-1} \mathrm{NaCl}$. None of the three amendments improved the bio-desorption of molinate from resin Amberlite XAD-4.

\section{Assessment of bio-regenerated resin Amberlite XAD-4 adsorption capacity}

The use of a higher concentration of adsorbed molinate was tested using about $650 \mathrm{mg}$ molinate per $\mathrm{g}$ of dry resin. Due to the low solubility of molinate, the adsorption was accomplished through three successive steps, otherwise it will be needed a large volume of molinate solution in contact with the resin. In the presence of this adsorbed molinate concentration, cells reached a biomass content of $1000 \mathrm{mgl}^{-1}$, about three times higher than that obtained under similar conditions, but in presence of $150 \mathrm{mg}$ molinate per g of dry resin. The use of high amounts of substrate and the respective conversion to biomass, permitted to evaluate 
the deterioration of the resin, namely due to the effect of metabolites and/or cellular debris on resin adsorption capacity. With this objective, after 20 days of incubation, when the equilibrium concentration of free molinate was below the detection limit, resin was washed, autoclaved, to inactivate eventual remaining cells, and a new cycle of adsorption was performed. The equilibrium concentration of free molinate, after adsorption of $225 \mathrm{mg}$ per $\mathrm{g}$ of re-utilised resin was around $150 \mathrm{mg}^{-1}$, which, according to isotherm equation, corresponds to approximately $500 \mathrm{mg}$ molinate per $\mathrm{g}$ of dry resin (Fig. 1B). These results indicate that the reutilised resin is behaving as if it had already about $275 \mathrm{mg}$ molinate per $\mathrm{g}$ of dry resin, a value considerably higher than 60-70 mg per gram of dry resin which was observed to be the bio-regeneration limit. Abiotic controls, run in parallel, gave results consistent with those expected considering the isotherm equation. In this case, the equilibrium concentration of free molinate, after adsorption of $100 \mathrm{mg}$ per gram of re-utilised resin was around $400 \mathrm{mgl}^{-1}$, which, according to isotherm equation, corresponds to approximately $685 \mathrm{mg}$ molinate per $g$ of dry resin. The results obtained show that the resin can be re-utilised, although a progressive deterioration can occur, due to metabolic activity. In fact, losses of adsorbent capacity during bio-regeneration has been attributed to decay products of microbial cells $[9,11]$.

A commonly accepted model for bio-regeneration processes proposes that desorption from the adsorbent is followed by diffusion to bulk liquid where further biodegradation may occur $[9,11,16]$. According to this model, bacteria would play an important role in facilitating desorption by reducing bulk liquid solute concentration, leading to continuous desorption. Through this simplified model it is possible to explain the results observed in the present study. The reduction of molinate concentration in bulk liquid due to bacterial activity, promoted the continuous desorption of the herbicide until the equilibrium concentration became below the bioavailability. As would be expected, different growth rates were observed for mixed culture DC in presence of free and adsorbed molinate. These differences can be explained based on molinate availability. In fact, in the presence of adsorbed molinate and for the operating conditions used in this study, growth rate is eventually controlled by molinate desorption and diffusion to the bulk liquid. The equilibrium concentration below the bioavailability was lower than $0.9 \mathrm{mgl}^{-1}$ (detection limit of the HPLC) and corresponded to average values of approximately $60-70 \mathrm{mg}$ of molinate per $g$ of dry resin. In this way, and using the concentration values of free molinate predicted by the isotherm equation, the limit of molinate bioavailability was between 0.3 and $0.4 \mathrm{mgl}^{-1}$. According to previous studies with activated carbon [12] is reasonable to hypothesise that at least part of that amount of molinate (approx. 60-70 $\mathrm{mg} \mathrm{g}^{-1}$ dry resin) remaining adsorbed on resin Amberlite XAD-4 may occupy the micropores, becoming unavailable for biodegradation. Preliminary attempts to use surfactants as SDS and Tween 80 did not favour the molinate desorption. Previous reports show that synthetic surfactants as SDS, Tween 80 or Triton X 100 promote desorption, when used at concentrations above critical micellar concentration [22-24]. The concentration of surfactants used in the present study, was eventually too low to promote desorption, however it was important to minimise cell damage or inactivation, avoiding negative consequences on molinate degradation. Despite of these preliminary results, further studies on the influence of different physical or chemical conditions on desorption extent may prove useful in this work.

\section{Conclusions}

1. Resin Amberlite XAD-4 was observed to be a good adsorbent for molinate, and the adsorption isotherm is well described by the Freundlich equation. Adsorption is reversible. Temperature, $\mathrm{pH}$ and conductivity, within the ranges studied, did not affect molinate adsorption.

2. Mixed culture DC was able to use previously adsorbed molinate, regenerating the resin Amberlite XAD-4.

3. Mixed culture DC consumed adsorbed molinate by promoting its continuous desorption until approximately $60 \mathrm{mg}$ of molinate per $\mathrm{g}$ of dry resin was reached, which corresponds to approximately $0.3-$ $0.4 \mathrm{mgl}^{-1}$ of molinate in free solution. Initial molinate concentration did not affect the extent of desorption.

4. Bio-regenerated resin maintains the adsorptive ability, although its capacity decreases due to metabolic activity and/or decay products of microbial cells.

5. The results obtained throughout this study show that the implementation of a combined system for molinate decontamination, consisting of adsorption followed by bio-regeneration, should be feasible. This methodology may be improved by the use of physical (as high temperature) or chemical (as surfactants) conditions which favour molinate desorption, and bio-regeneration extent.

\section{Acknowledgements}

We gratefully acknowledge Pablo Galego for technical assistance. This work was financially supported by Fundação para a Ciência e a Tecnologia from Ministér- 
io da Ciência e do Ensino Superior, Portugal (project POCTI/34274/AGR/2000).

\section{References}

[1] Ware GW. The pesticide book. Fresno, USA: Thomson publications; 1994 pp. 103-126.

[2] Mabury SA, Cox JS, Crosby DG. Environmental fate of rice pesticides in California. Rev Environ Contamin and Toxicol 1996;147:71-117.

[3] Paune F, Caixach J, Espadaler I, Om J, Rivera J. Assesment on the removal of organic chemicals from raw and drinking water at a Llobregat river water works plant using GAC. Water Res 1998;32(11):3313-24.

[4] Cerejeira MJ, Viana P, Batista S, Pereira T, Silva E, Valerio MJ, Silva A, Ferreira M, Silva-Fernandes AM. Pesticides in Portuguese surface and ground waters. Water Res 2003;37(5):1055-63.

[5] Cochran RC, Formoli TA, Pfeifer KF, Aldous CN. Characterization of risks associated with the use of molinate. Regulatory Toxicol Pharmacol 1997;25(2): 146-57.

[6] Craveiro de Sa FA, Malina Jr JF. Bio-regeneration of granular-activated carbon. Water Sci Technol 1992; 26(9-11):2293-5.

[7] Croll BT, Chadwick B, Knight B. The removal of atrazine and other herbicides from water using granular activated carbon. Water Supply 1992;10:111-20.

[8] Rexwinkel G, Heesink BBM, Swaaij WPM. Adsorption of halogenated hydrocarbons from gaseous streams by Amberlite XAD-4 and Activated Carbon: equilibria. J Chem Eng Data 1999;44(6):1146-50.

[9] Roy D, Maillacheruvu K, Mouthon J. Bioregeneration of granular activated carbon loaded with 2,4-D. J Environ Sci Health B 1999;34(5):769-91.

[10] Belmouden M, Assabbane A, Ichou YA. Adsorption characteristics of a phenoxy acetic acid herbicide on activated carbon. J Environ Monitor 2000;2(3):257-60.

[11] Sirotkin AS, Koshkina LY, Ippolitov KG. The BACprocess for treatment of waste water containing nonionogenic synthetic surfactants. Water Res 2001; 35(13):3265-71.

[12] Klimenko N, Winther-Nielsen M, Smolin S, Nevynna L, Sydorenko J. Role of the physico-chemical factors in the purification process of water from surface-active matter by biosorption. Water Res 2002;36(20):5132-40.

[13] Matsui Y, Knappe D, Takagi R. Pesticide adsorption by granular activated carbon adsorbers. 1. Effect of natural organic matter preloading on removal rates and model simplification. Environ Sci Technol 2002;36(15):3426-31.
[14] Gimeno O, Plucinski P, Kolaczkowski ST, Rivas FJ, Alvarez PM. Removal of the Herbicide MCPA by Commercial Activated Carbons: equilibrium, kinetics, and reversibility. Ind Eng Chem Res 2003;42(5):1076-86.

[15] Feakin SJ, Gubbins B, MacGhee I, Shaw LJ, Burns RG. Inoculation of granular activated carbon with-s-triazinedegrading bacteria for water treatment at pilot-scale. Water Res 1995;29(7):1681-8.

[16] Holst J, Martens B, Gulyas H, Greiser N, Sekoulov I. Aerobic biological regeneration of dichloromethaneloaded activated carbon. J Environ Eng-ASCE 1991;117(2):194-208.

[17] Barreiros L, Nogales B, Manaia CM, Silva-Ferreira AC, Pieper DH, Reis MA, Nunes OC. A novel pathway for mineralization of the thiocarbamate herbicide molinate by a defined bacterial mixed culture. Environ Microbiol 2003;5(10):944-53.

[18] Brás IP, Santos L, Alves A. Organochlorine pesticides removal by pinus bark sorption. Environ Sci Technol 1999;33(4):631-4.

[19] Konstantinou IK, Albanis TA. Adsorption-desorption studies of selected herbicides in soil-fly ash mistures. J Agri Food Chem 2000;48(10):4780-90.

[20] Konstantinou IK, Albanis TA, Petrakis DE, Pomonis PJ. Removal of herbicides from aqueous solutions by adsorption on Al-pillared clays, Fe-Al pillared clays and mesoporus alumina aluminum phosphates. Water Res 2000;34(12):3123-36.

[21] González-Pradas E, Villafranca-Sánchez M, Del ReyBueno F, Ureña-Amate MD, Socías-Viciana M, Fernández-Pérez M. Removal of diquat and deisopropylatrazine from water by montmorillonit-(Ce or $\mathrm{Zr}$ ) phosphate crosslinked compounds. Chemosphere 1999;39(3):455-66.

[22] Grosser RJ, Friedrich M, Ward DM, Inskeep WP. Effect of model sorptive phases on phenanthrene biodegradation: different enrichment conditions influence bioavailability and selection of phenanthrene-degrading isolates. Appl Environ Microbiol 2000;66(7):2695-702.

[23] Sanchez-Camazano M, Sanchez-Martin MJ, RodriguezCruz MS. Sodium dodecyl sulphate-enhanced desorption of atrazine: effect of surfactant concentration and of organic matter content of soils. Chemosphere 2000;41: 1301-5.

[24] Mata-Sandoval JC, Karns J, Torrents A. Influence of rhamnolipids and triton $\mathrm{X}-100$ on the desorption of pesticides from soils. Environ Sci Technol 2002;36(21): 4669-75.

[25] Pinto L. Sistema Combinado de Membranas e Adsorção com Modulação de Pressão e Temperatura. Aplicação à Separação de Alguns COVs do Ar. PhD Thesis, Faculdade de Engenharia-Universidade do Porto, Portugal, 2000. 